\title{
Urgent Need for a Performance-Based Approach for Seismic Assessment and Design of Fastenings Used in Structural Applications
}

ISSN: 2639-0574

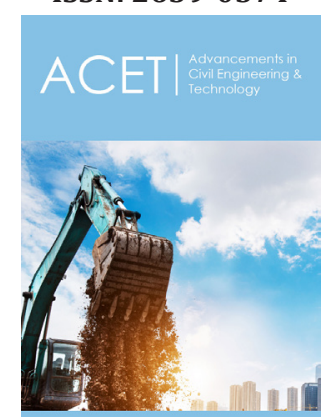

${ }^{* 1}$ Corresponding author: Akanshu Sharma, Innovative Strengthening Methods with Fastenings, Institute of Construction Materials, University of Stuttgart, Germany

Submission: 眥 April 17, 2019

Published: 制April 22, 2019

Volume 3 - Issue 1

How to cite this article: Akanshu S. Urgent Need for a Performance-Based Approach for Seismic Assessment and Design of Fastenings Used in Structural Applications. Adv Civil Eng Tech. 3(1). ACET.000555.2019.

DOI: 10.31031/ACET.2019.03.000554

Copyright@ Akanshu Sharma, This article is distributed under the terms of the Creative Commons Attribution 4.0 International License, which permits unrestricted use and redistribution provided that the original author and source are credited.

\section{Akanshu Sharma*}

Innovative Strengthening Methods with Fastenings, Institute of Construction Materials, University of Stuttgart, Germany

\section{Opinion}

Fasteners or anchors are widely used to form the connections between non-structural or structural components and the primary reinforced concrete structure. The design of fastenings in concrete is traditionally performed using force-based method, where the design load for the fastening is calculated corresponding to different possible failure modes and the lowest value defines the allowable load that can be applied for the anchorages [1-4]. Under seismic actions, the fasteners in concrete are subjected to relatively strong demands of cycling tension and shear loads as well as opening and closing of cracks intercepting the fasteners (Figure 1).

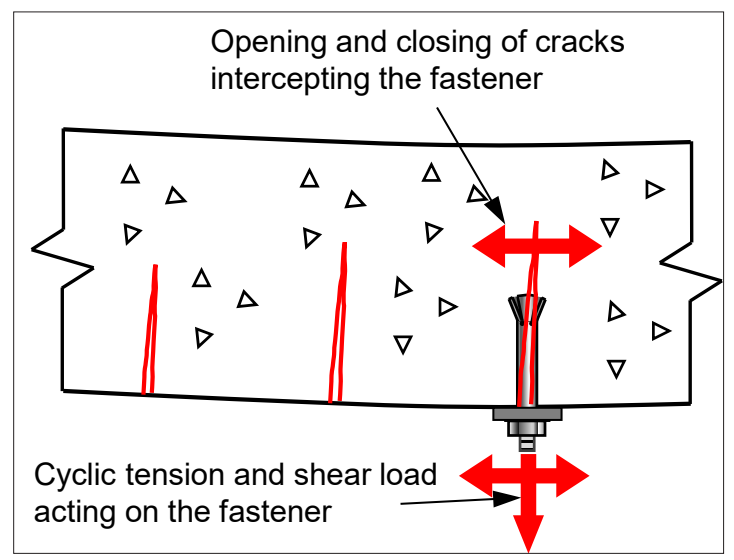

Figure 1: Typical demands on fasteners under seismic actions.

Although the seismic design philosophy for reinforced concrete structures relies heavily on the ductility and nonlinear performance of the structure, the current philosophy for seismic assessment and design of fasteners is primarily force-based, with an indirect check of displacements performed in certain cases [5]. This approach might be sufficient for the assessment of non-structural connections where the maximum load acting on the fasteners can be reasonably estimated. However, for the fasteners used to form structural connections, this approach can be rather unreliable as it does not provide the required information necessary for the assessment of structural connections. Once the structure goes beyond elastic limit, forces acting on the structural connections and therefore on the fasteners become less relevant while the displacement demands and the hysteretic behavior become important. As the fastening itself goes beyond its elastic limit, a force-based assessment method and design becomes less informative than required. This applies equally to structural connections formed using post-installed fasteners as well as with post-installed reinforcing bars such as column-foundation connections, beam-wall connections etc.

The current seismic assessment and design methods become even less reliable for the fastenings used to connect the strengthening/retrofitting elements to the structural 
members. This is due to the high demands placed on the fasteners used to form structural strengthening connections. As the structure goes in inelastic range, the fasteners are subjected to the demands of high forces that are cyclic in nature. Additionally, invariably, the fasteners are intercepted by the cracks, which may be of relatively large widths and also open and close with the structural deformations. In certain applications, the cycling of tension load and the cycling of cracks can be in-phase, i.e. the fastener is loaded to the maximum tension force at the same moment when the crack intercepting the fastener is opened to its maximum. In case of reinforced concrete frame structures, the physical dimensions of the structural members could be rather limited leading to a limited area to transfer the tension forces from the fasteners into the concrete member. Thus, while the demands placed on the fasteners forming structural strengthening connections are rather high, their capacity remains limited.

A reliable assessment of the fastener subjected to such strong demands cannot be made simply on the basis of a force- based method that does not give sufficient consideration to the displacement behavior and provides no information about the hysteretic behavior of the fasteners. It is possible that fastenings formed using different types of fasteners have theoretically the same load-carrying capacity but totally different displacement and hysteretic behavior. This was clearly brought out in the tests performed by Sharma [6] and Genesio [7] on beam-column joints retrofitted using fully fastened haunch retrofit solution (FFHRS), where the steel haunch elements were connected to the frame members using three different types of post-installed fasteners. The typical demands on the post-installed fasteners used in FFHRS are depicted in Figure 2. As seen, when the haunch element is loaded in tension, the fasteners used to connect the haunch element and the structure are subjected to high tension forces, while the cracks intercepting the fasteners are opened wide. Due to the limited dimensions of the structural members, the area of force transfer zone of the fasteners is also rather limited.

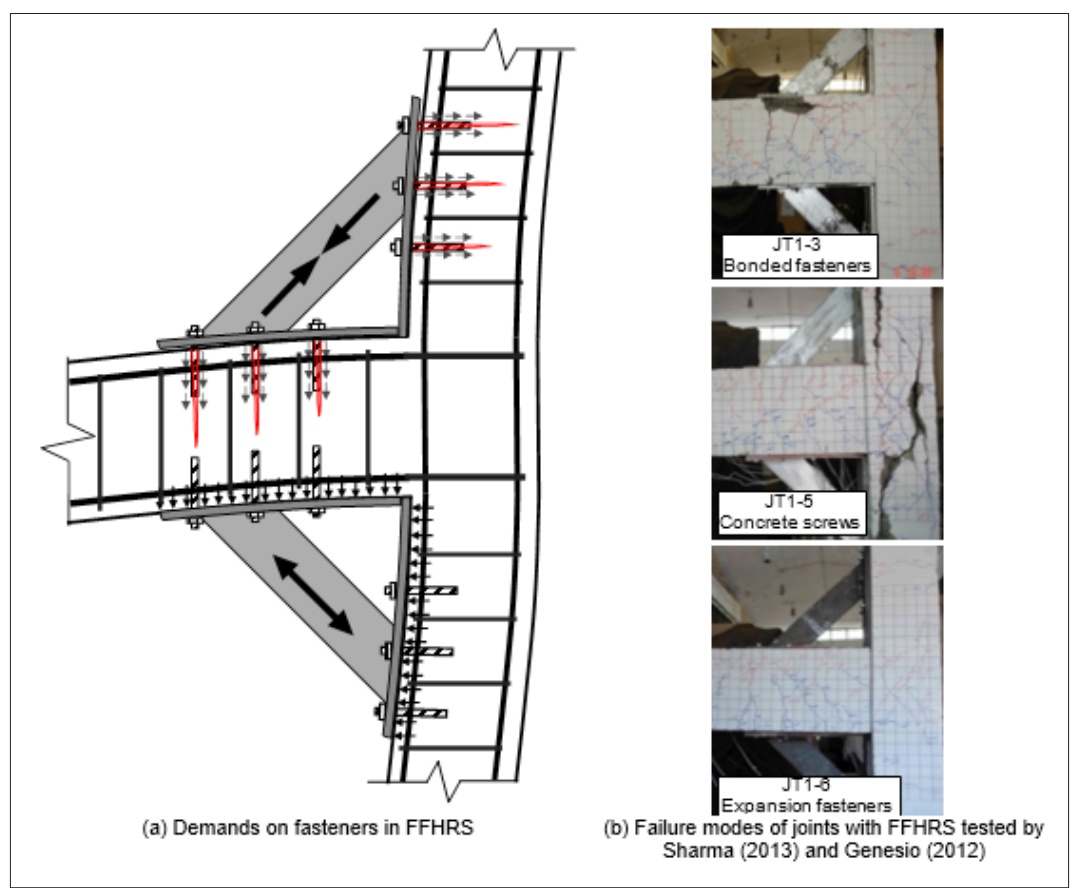

Figure 2: Influence of fastener performance on the performance of retrofitting solution.

Sharma [6] and Genesio [7] tested exterior reinforced concrete beam-column joints retrofitted using FFHRS. The joints tested had the same geometry and reinforcement detailing. Also, the design of the haunch elements used to form the strengthening solution was exactly the same for all the cases. However, three different types of fasteners namely bonded fasteners, concrete screws and expansion fasteners were used to form the connection between the haunch element and the structural members. The load carrying capacity of the fastening calculated using the current force-based methods was almost the same for all the fastenings irrespective of the type of fasteners used and concrete cone failure was the expected failure mode in each case. Figure 2 shows the results of the tests in terms of the failure mode. It can be seen that even though the theoretical load carrying capacity for all the anchorages was very similar and the design of the joints and strengthening elements used in the tests was essentially the same, each specimen showed a different performance and failed with a different failure mode. Also, the load-displacement behavior of the three joints tested was rather different from one another. These test results clearly highlight that the actual performance of a retrofitting solution with retrofitting element connected using the fasteners to the structural member depends largely on the performance of the fastening itself. The current force-based seismic design and assessment methods are unable to account for this difference in the performance of the fasteners.

Thus, in order to ensure the safety of the structural and strengthening connections, an approach that can give due 
consideration to the fastener performance in seismic assessment and design is essential. The performance-based approach can be included in seismic assessment by carrying out seismic tests on fasteners in displacement domain over the entire range of interest (pre-peak, around peak and post-peak region of the loaddisplacement curves). Such tests will provide information not only on the load and displacement behavior of the fasteners under cyclic loads but will also provide essential information on the hysteretic behavior. With such an information, the suitability of fasteners for structural connection applications can be judged with much more confidence and reliability. The information obtained by such assessment tests can also be used to carry out displacementcontrolled analysis of structural components giving due consideration to the nonlinear behavior of the connections $[8,9]$. In summary, there is an urgent need for developing performancebased methods for seismic assessment and design of fastenings used in structural and strengthening applications.

\section{References}

1. ACI 318 (2014) Building code requirements for structural concrete. American Concrete Institute, Michigan, USA.
2. Eligehausen R, Mallée R, Silva JF (2006) Anchorage in Concrete Construction, Ernst \& Sohn, Berlin.

3. EN 1992-4 (2018) Eurocode 2 design of concrete structures-part 4 design of fastenings for use in concrete. European committee for standardization, Brussels.

4. Fib Bulletin 58 (2011) Design of anchorages in concrete-Guide to good practice, fib Special Activity Group 4. International federation for structural concrete, Lausanne, Switzerland.

5. ETAG 001 (2013) Guideline for European technical approval of metal anchors for the use in concrete. Edition 2012, Annex E: Assessment of Metal Anchors under Seismic Action, AMD.

6. Sharma A (2013) Seismic behavior and retrofitting of RC frame structures with emphasis on beam-column joints-experiments and numerical modeling. PhD Thesis, IWB, University of Stuttgart, Germany.

7. Genesio G (2012) Seismic assessment of RC exterior beam-column joints and retrofit with haunches using post-installed anchors. PhD Thesis, IWB, University of Stuttgart, Germany.

8. Sharma A, Eligehausen R, Hofmann J (2014) Numerical modeling of joints retrofitted with haunch retrofit solution. ACI Structural Journal 111(4): 861-872.

9. Sharma A (2017) Performance based approach for anchorage in concrete construction. $3^{\text {rd }}$ Int Sym on Connections between Steel and Concrete, pp. 27-29. 